\title{
The impact of employment on cognition and cognitive reserve: implications across diseases and aging
}

This article was published in the following Dove Press journal:

Nursing: Research and Reviews

29 November 2016

Number of times this article has been viewed

\section{David E Vance' \\ Jennifer Bail' \\ Comfort C Enah' \\ Jennifer J Palmer ${ }^{2}$ \\ Anna K Hoenig'}

'School of Nursing, University of Alabama at Birmingham, ${ }^{2} \mathrm{School}$ of Nursing, University of Alabama in Huntsville, Huntsville, AL, USA
Correspondence: David E Vance School of Nursing, 1720 2nd Avenue South, University of Alabama at Birmingham, Birmingham, AL 35294-1210, USA

Tel +l 2059347589

Email devance@uab.edu
Abstract: Employment requires one to learn new skills, establish a routine, and engage socially, all of which can also provide purpose or meaning to one's life and provide income. All of these can directly or indirectly bolster cognitive reserve, which may protect cognitive health, especially as one ages. Unfortunately, if one is incapacitated due to illness, such as depression, HIV, or other diseases and chronic conditions, it may necessitate reduction/withdrawal from employment, which could limit employment-induced cognitive health benefits. This article examines these issues within the framework of neuroplasticity and cognitive reserve, thus providing implications for practice and research for nurses and health care professionals.

Keywords: HIV, breast cancer, depression, neuroplasticity, occupation, morbidities, health behaviors

\section{Introduction}

In the cognitive aging literature, it is well established that engaging in complex activities in one's environment can produce changes in the brain that also promote cognition. ${ }^{1}$ Yet, when considering the amount of time in which people engage in any activity, employment is by far the largest activity with many people spending 40-70 hours a week, month after month, year after year, heavily engaged in demanding, often complex tasks that may require considerable focus and expertise. Certainly, this dosage of engagement produces changes in the brain that may also facilitate brain health and optimal cognitive functioning. Unfortunately, those who have to reduce their level of employment due to poor health may not have the opportunity to reap some of those cognitive benefits derived from employment.

The purpose of this article is to examine how employment (often referred to as occupation or work) can promote cognitive reserve and health, and how this may be compromised due to illness. To do so, first an explanation of neuroplasticity and cognitive reserve is provided as a framework to interpret how employment benefits cognitive health. Second, the role of employment on cognitive reserve is examined with a sampling of studies that highlight the cognitive benefits of employment. Third, unique benefits of employment that promote positive neuroplasticity are described (Figure 1). Fourth, a discussion is provided about how unemployment or the lack of cognitive stimulation can produce cognitive problems in those with certain diseases and chronic conditions (e.g., depression, HIV, breast cancer). Finally, implications for health care practice and research in this area are posited, especially as they relate to aging. 


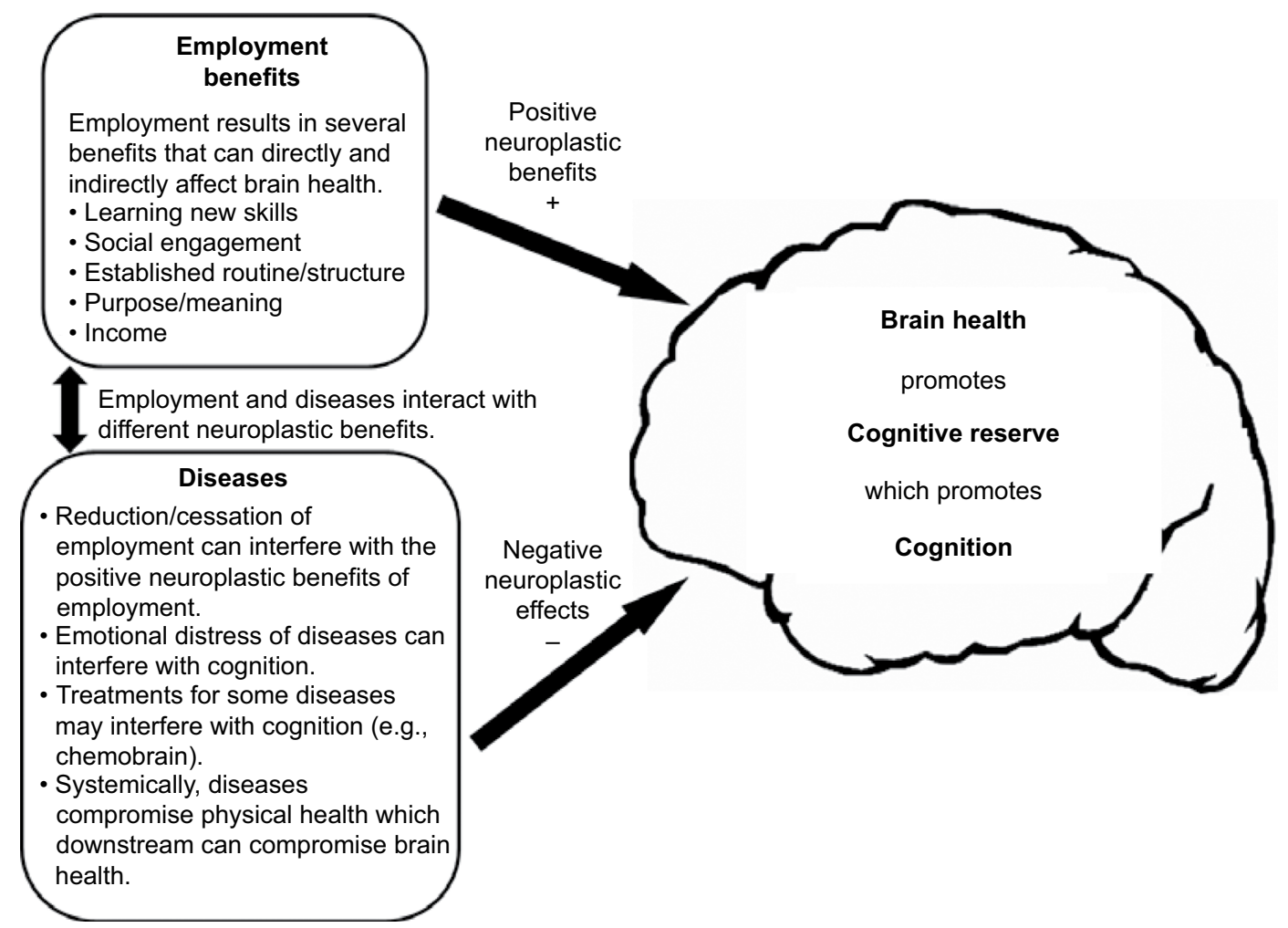

Figure I The interaction of employment and diseases on cognitive reserve.

\section{Neuroplasticity and cognitive reserve}

Cognitive reserve, also referred to as brain reserve, denotes the brain's ability to continue to perform cognitive processes in lieu of neurological insults, such as normal aging, prolonged systemic inflammation, and disease processes. In fact, many diseases and chronic conditions can alter mitochondrial functioning and create a systemic inflammatory response that over time can compromise neuronal integrity, reduce cognitive reserve, and impair cognitive functioning. ${ }^{2,3}$ Cognitive reserve can be increased or decreased in lieu of activities that either require one to adapt to the environment or to disengage from the environment in response to lack of stimulation. These processes are referred to as either positive neuroplasticity or negative neuroplasticity and create observable morphological changes in response to environmental stimuli, which can also impact cognition. ${ }^{4}$

Animal studies demonstrate these processes of positive or negative neuroplasticity. Using the seminal Enriched Environmental Paradigm, researchers compared cognitive reserve in genetically similar rats (i.e., from the same colony) when placed in one of three conditions: 1) enriched; 2) standard; or 3) impoverished. 5,6 The enriched environment consists of a large cage with a community of rats and several toys with which to interact. The standard environment consists of a cage with three rats in it and no toys with which to interact. The impoverished environment consists of a cage with rats placed in isolation with no toys with which to interact. When placing rats in isolation or in a community of other rats for 4-8 weeks, $\mathrm{Lu}$ et al found that rats placed in the enriched environment experienced the most brain morphological growth as exhibited by more neurogenesis in the hippocampus; this reflects positive neuroplasticity. ${ }^{7}$ Similarly, compared to rats in the other two conditions, Kobayashi et al observed rats placed in such an impoverished environment exhibited the least brain morphological growth and the poorest cognition as exhibited by slower maze running; this reflects negative neuroplasticity. ${ }^{6}$

Human studies, such as the older juggler study, also exemplify these neuroplastic principles. In this seminal study, Boyke et al conducted brain MRIs on 69 community-dwelling older adults $\left(\mathrm{M}_{\text {age }}=60\right.$; range $\left.=50-67\right)$ at three separate times: Time 1 - before the older adults learned to juggle; Time 2 $\sim 3$ months later after they successfully learned to juggle in a three-ball cascade pattern for 1 minute; and Time $3-\sim 3$ months later during such time they were instructed to avoid juggling. ${ }^{8}$ From Time 1 to Time 2, these researchers observed growth in the hippocampus and nucleus accumbens, brain structures necessary for memory formation; growth during this period is reflective of positive neuroplasticity. Albeit, from Time 2 to Time 3, atrophy in these same brain regions was observed; brain atrophy during this period is reflective of negative neuroplasticity. These and other studies highlight the importance that novel and stimulating engagement have 
on improving cognitive reserve and increasing/preserving cognitive functioning. ${ }^{9-11}$

\section{Employment and cognitive reserve}

As stated in the prior section, engagement in stimulating and cognitively demanding activities can improve cognition, which may likewise improve cognitive reserve; such activities associated with employment can produce similar results. In a sample of 18,259 participants in the Survey of Health, Ageing, and Retirement in Europe Study, Leist et al examined whether gaps in employment from unemployment or sickness, compared to those without such gaps in employment, were associated with cognitive functioning. ${ }^{10}$ After controlling for socioeconomic status in early life, school performance, and education, these researchers observed such employment gaps predicted poorer cognitive functioning.

Likewise, in the Health and Retirement Study, Fisher et al examined cognition before and after retirement in 4,182 adults to determine whether the occupational cognitive demands were neuroprotective over time, from 1992 to $2010 .{ }^{9}$ Occupational cognitive demands were also categorized using the O'NET SOC occupational codes. From these hierarchical taxonomic occupation-specific descriptors, Fisher et al observed that those with higher occupational demands experienced better cognitive functioning before retirement. Likewise, controlling for gender, age, education, and depressive symptoms, those with higher occupational demands also experienced slower cognitive decline over time after retirement. These and other studies reflect the premise that engagement in employment stimulates the brain and supports the formation and maintenance of an optimal cognitive reserve.

\section{Positive neuroplastic effects of employment}

Active engagement produces positive neuroplastic effects benefiting cognition and cognitive reserve. Based upon the literature, Vance et al described five mechanisms in which employment supports cognitive reserve: 1) learning new skills; 2) social engagement; 3 ) established routine/structure; 4) purpose/meaning; and 5) income (Figure 1). ${ }^{12}$

\section{Learning new skills}

As already highlighted in earlier sections, learning new skills (e.g., juggling) produces cognitive improvements and changes in brain morphology. As part of employment, employees must constantly adapt to changing environmental demands, whether it is learning new computer skills, adapting to new workplace policies, adjusting to new trends in the market place, or familiarizing oneself with a new product line. Whatever the type of employment, change is constant and skill acquisition, whatever the skill(s), is needed to adapt.

In fact, skill acquisition was observed to improve cognitive function in 41 older adults (60-84 years) who were novices to reading music or playing a musical instrument. In their study, Seinfeld et al randomized these participants to either a piano training group or a control group. ${ }^{11}$ Participants in the piano training group received an individualized weekly lesson along with 45 minutes of daily practice over 4 months. Participants in the control group engaged in leisure activities (i.e., dance, yoga) over 4 months. Compared to baseline, those in the piano training group improved on a measure of executive functioning (i.e., Stroop) and experienced less depressive symptomatology. If cognition can be improved with acquiring this new skill, it is logical to assume that cognition can be improved with learning employment-related skills.

\section{Social engagement}

Independent of the task-focused activities associated with employment, the mere social interaction with colleagues, coworkers, and clients supplies an additional source of cognitive stimulation. To socially engage, one must attend to both semantic and emotional vocalizations, interpret body language, recall details from past conversations, anticipate responses from both self and others, emotionally regulate such interactions, and organize all of this information in order to coordinate beneficial outcomes. Such social engagement has been suggested to facilitate higher-ordered cognition, such as executive functioning. ${ }^{13}$ In fact, some studies demonstrate that those with larger social networks may benefit from better overall perceptual speed, episodic memory, and working memory. ${ }^{14,15}$ Likewise, in a sample of 2,513 adults in the Honolulu-Asia Aging Study, Saczynski et al observed that those with decreased social engagement in mid to late life exhibited the highest risk profile for cognitive decline years later, which supports the notion of an active social engagement being supportive of better cognitive reserve. ${ }^{16}$

\section{Established routine/structure}

A structured routine itself, as established by an employment schedule, can facilitate a healthy lifestyle. It facilitates when to eat, sleep, take medications, and recreate (e.g., going for a walk in the evening after work). Thus, if someone is "successfully" employed, he or she cannot stay up late with friends and expect to go to work early the next day and be functioning at peak performance. Employees with a set schedule have to intrinsically regulate certain social and physiological functions in order to remain employed. (Albeit, shift work presents 
its own set of issues, which is beyond the scope of this article [Wang et al].) Such regulation has been proposed in certain interactions to improve cognition indirectly by improving physiological function; thus, as a general principle, that which is good for the body is likewise good for the brain. ${ }^{18}$

\section{Purpose/meaning}

Engaging in employment is mostly considered a productive activity and as such, employment inherently has purpose and meaning attached to it. Purpose and meaning intrinsically provide an internal focus or perspective to one's everyday experience such that the influence of everyday stressors may be minimized. According to Matuska, this internal focus from meaningful employment assists with the development of mental constructs that help one to be more resilient and weather difficult times. ${ }^{19}$ During difficult times, such resiliency helps one to focus and prioritize on what one can do (i.e., work), and deemphasize what is less important (e.g., receiving a speeding ticket) or beyond what one can control (e.g., being diagnosed with diabetes). Fortunately, Hakanen and Wilmar observed in a longitudinal study of 2,555 Finnish dentists that those who considered their employment as meaningful were more likely to experience less depressive symptoms and occupational stress; likewise, those with more employment burnout were more likely to have more depressive symptoms. ${ }^{20}$ Thus, the resilience acquired from meaningful employment may also reduce stress, which may cause decreased activation of the hypothalamus-pituitaryadrenal (HPA) axis, resulting in less inflammatory cortisol production, which can be neuroprotective over time.,21,22 Thus, meaning and purpose derived from employment may, in some instances, serve as a psychological outlet (catharsis) to help one maintain emotional homeostasis and support routine health-promoting behaviors. Yet, this assumes that one's employment does not introduce excessive work-related conflict and stress that negates its potential positive benefits. The literature is replete with studies of the negative impacts that excessive stressful work demands exert on sleep, substance use, and cognition. ${ }^{23}$

\section{Income}

One area in which employment can reduce stress is by securing sufficient income for the necessities of life. As such, the stress generated from a lack of sufficient income can stimulate the HPA axis. A prolonged period of such financial stress with accompanying release of cortisol can cause systemic inflammation and neuroinflammation, which over time can deplete cognitive reserve. ${ }^{2,24}$ In fact, such financial stress has been shown to be a cause of anxiety that contributes to poor mood dysregulation, substance use, and other negative health behaviors, all of which negatively impacts cognitive reserve. ${ }^{18,25,26}$

Another way in which employment income can facilitate cognitive reserve is through stimulating active engagement with one's environment. Income can be used for fun things in life (e.g., exotic vacations). In this regard, income (especially extra, discretionary income) allows one to explore his or her environment in an enriched manner. One can socialize by hosting parties or going out to dinner with friends, take fun classes for learning new skills (i.e., photography), and engage in stimulating passive entertainment, such as books, theatre, or movies. Just as in the enriched environmental paradigm with rats (Neuroplasticity and cognitive reserve section), all of these activities, supported by income, may facilitate positive neuroplasticity and cognitive reserve; and as already shown in a variety of studies, active engagement in leisure time activities appears to support cognitive reserve. ${ }^{11,15,27}$

\section{Diseases, employment, and cognition}

Disease, and/or their treatments, can exert a direct physiological impact on brain health that can decrease cognitive reserve and impair cognitive functioning. ${ }^{28}$ Indirectly, diseases may also compromise cognition and cognitive reserve in two ways. First, the emotional problems of coping with such diseases may interfere with cognitive processes through rumination or increased cortisol processes through activation of the HPA axis, which can cause neuroinflammation. ${ }^{2}$ Second, as argued in this article, coping with such diseases can reduce the number of hours employed, interfere with one's ability to perform such employment duties, or precipitate an early and unexpected exodus from the employment environment, which unto itself may contribute to negative neuroplasticity if such engagement is not replaced with other stimulating activities (Figure 1). Although this can be discussed in a variety of diseases, such as multiple sclerosis, for the sake of brevity, this discussion is limited to depression, HIV, breast cancer, and aging due to the authors' expertise in these areas. ${ }^{29}$

\section{Depression and employment}

Globally, depression is a severe and common psychiatric disorder that affects millions of people. Depression has been linked to unemployment and productivity loss. ${ }^{30,31}$ Lerner et al advanced several mechanisms that may be responsible for such adverse job-related outcomes among depressed persons; these include poor job performance, discrimination, difficulty 
coping with job pressures, and job accommodation barriers. ${ }^{32}$ Fortunately, employment outcomes also appear to improve after depressive symptoms decrease. In several primary care settings involving depression treatment trials, patients whose symptoms improved had higher rates of employment. ${ }^{33,34}$

Although depression primarily involves mood disturbances, cognitive impairment has also been documented as a common feature of major depression that can result in unemployment. ${ }^{35,36}$ Measurable impairments have been found in speed of processing, sustained and selective attention, learning and memory, and executive function. ${ }^{31}$ Such cognitive impairment can be disruptive to occupational functioning. When Lam et al examined how symptoms interfered with occupational functioning among employed adults with major depression, their findings indicated that problems with concentration and memory were the major culprits. ${ }^{37}$ Associations between cognitive impairment and poorer occupational outcomes were found in a systematic review of studies that explored the relationship between objectively measured cognitive impairments and occupational functioning in people with major depression. ${ }^{31}$ Coupled with the effect of depression on employment, the reduction in employment or possible declines in the complexity of job duties may further create a negative neuroplastic response, which over time can compromise cognitive reserve and cognitive functioning.

\section{HIV and employment}

With the obvious health concerns and stigma associated with $\mathrm{HIV}$, it is not surprising that across each decade of life, the prevalence of depression and anxiety in this population is $\sim 40 \%$ and $20 \%$, respectively. ${ }^{38}$ Such emotional sequelae may contribute to poor cognitive reserve; however, the regulation of such negative emotions may be exacerbated by some of the specific neurological sequelae caused by HIV. Many with HIV experienced damage to the fronto-striatal circuitry; this is the region of the brain largely involved with executive functioning (e.g., problem solving, reasoning). ${ }^{39}$ In fact, other studies emphasize that some adults with HIV exhibit specific cognitive impairments in poorer decision making. ${ }^{40}$

Impaired executive functioning and decision making, coupled with prolonged negative thoughts and emotions that can often accompany this disease, may contribute to negative rumination, which can further exacerbate depression and suicidal ideation in this clinical population. ${ }^{41}$ Albeit, an established employment routine may mitigate some of these negative outcomes. Using the Australian HIV Observational Database, McManus et al found that accidental/violent death or suicide was significantly related (odds ratio $[\mathrm{OR}]=5.86$ ) to being unemployed. ${ }^{42}$ Conversely, in a sample of 118 adults with HIV looking for a job over a 2-year period, van Gorp et al found that enjoyment and quality of life improved for those who gained employment compared to those who did not. ${ }^{43}$

In a related study of 139 adults with HIV, Fazeli et al examined the impact of active lifestyle factors on whether one was diagnosed with HIV-associated neurocognitive disorder (HAND) as ascertained by norm-based cognitive testing. ${ }^{44}$ Active lifestyle factors included whether they were employed full- or part-time, physically exercised, or were socially engaged; each was measured dichotomously (yes/ no). Those engaged in all three active lifestyle factors had the lowest prevalence of HAND at $20 \%$; however, as people engaged in fewer active lifestyle factors, the prevalence of HAND increased substantially from 33\% with two, 51\% with one, and $63 \%$ with no engagement in these lifestyle factors. Although employment was just one of three active lifestyle factors examined, this study does lend support to the idea that work engagement is important to building and/ or maintaining cognitive reserve.

\section{Breast cancer survivors and employment}

Advancements in treatment have increased 5-year breast cancer survival to $\sim 90 \%$, leading to an increased focus on the management of long-term effects of treatment. ${ }^{45}$ Unfortunately, up to $90 \%$ of breast cancer survivors (BCS) experience long-term cognitive impairment and complaints. ${ }^{46-48}$ Such cognitive complaints negatively impact employment, daily function, and quality of life of BCS. ${ }^{49,50}$

Employment plays a key role in financial and psychological well-being and in a return to "normalcy" during or following cancer treatment. ${ }^{49}$ Although $45 \%-93 \%$ of BCS choose to return to work within 12 months of diagnosis, cognitive impairments can make job-related duties more difficult and take longer to complete. ${ }^{50-53} \mathrm{BCS}$ ' decision to return to work is influenced by cognitive impairments following treatment, self-awareness of cognitive impairments, and the impact of perceived cognitive impairments on their confidence to succeed at work. ${ }^{54} \mathrm{BCS}$ are more likely than their age-matched peers to experience changes in employment, including retirement, reduction of hours, and change of position. ${ }^{55,56}$ Loss of employment greatly affects financial security and access to health insurance, especially for many BCS who are the sole family provider; this can increase stress, which overtime can promote negative neuroplasticity. ${ }^{2,50}$ Furthermore, nonemployed BCS report lower physical and mental quality of life and higher levels of fatigue and anxiety than employed $\mathrm{BCS}$; this is important because fatigue and anxiety negatively 
impact cognition. ${ }^{18,57}$ As BCS experience reduced employment, suffer from fatigue and anxiety, and experience varying levels of cognitive impairments associated with treatment, the amount of positive cognitive stimulation (e.g., interactions with coworkers, learning new tasks) and physiological support to the brain (e.g., having a steady/consistent sleep schedule) may be reduced as a result.

\section{Aging and employment}

Although aging itself is a disease factor that impacts employment, increasing age is associated with the development of some diseases, disengagement from employment, and the gradual loss of some cognitive functioning. Engagement in cognitively stimulating activities after retirement and/or in later years may also be important for minimizing or delaying age-related cognitive declines and dementia, whether or not these activities are employment related. For example, Wilson et al examined whether early-life (childhood, early adulthood) and later-life (middle-age, older age) cognitive engagement (e.g., reading books, visiting a library) influenced cognitive functioning in 294 community-dwelling older adults. ${ }^{58}$ In this longitudinal design, participants received cognitive assessments annually until they died $\left(\mathrm{M}_{\text {age }}=89.3\right)$, at which point they were autopsied to assess their neuropathological burden, such as gross and microscopic infarction, tau positive tangle density, $\beta$-amyloid burden, and neocortical Lewy body burden. These researchers observed that early- and late-life cognitive engagement accounted for $14 \%$ of the variance in cognitive functioning over time. The augmentation of cognitive reserve may also prevent or delay the onset of age-related dementia.

Similarly, Lindstrom et al examined the amount of time engaged in 26 leisure time activities during midlife (40-59 years) in 135 adults with Alzheimer's disease and 331 healthy controls. ${ }^{59}$ For each hour of engaging in passive television watching, these researchers noted a 1.3 increased probability of developing Alzheimer's disease. Although the cognitive complexity of the television programming was not accessed (e.g., The Bachelor vs Jeopardy), the amount of time engaging in less cognitively stimulating activities has merit, especially for a population with limited financial resources.

\section{Implications for practice}

The neuroplastic stimulation provided from employment can augment cognition and cognitive reserve. Based on that, two important considerations for practice should be considered: 1) strategies to reintegrate and transition back to employment or 2) compensate for the loss of employment with other activities that provide neuroplastic stimulation.
Albeit, both considerations must take into account the motivation of whether the patient wants to return to work, if it is physically or mentally feasible for the patient to engage in work, especially at the level of his or her previous level of engagement, or whether it is developmentally appropriate for one to disengage from employment as he or she is close to retirement age. Also, for many with low wage jobs and from low socio-economic backgrounds, chronic diseases may be more common and thus the choice to quit work or return to work is beyond the patient's choice; at which point, case managers and financial specialists may need to be included in the care plan.

\section{Employment reintegration}

For some patients who are healthy enough, employment reintegration can benefit them emotionally and cognitively. Likewise, improvements in psychological and cognitive functioning may facilitate such employment reintegration. For example, Hees et al observed in 117 adults with major depressive disorder that a reduction in depressive symptomatology and anxiety, and greater work motivation, significantly predicted one's ability to return to work. ${ }^{30}$ Although treatment for depression is generally associated with improved work outcomes, including gains in productivity, specific treatments for depression-related cognitive impairment that can optimize occupational functioning are needed. . $^{31,60,61}$

Cognitive impairments that result from diseases can be managed using nonpharmacological strategies, such as remediation techniques, compensatory strategies, and adaptive approaches, which may facilitate employment reintegration. For example, Elgamal et al conducted a study to assess the effects of a 10-week course of computer-based cognitive remediation with depressed patients. ${ }^{62}$ These researchers found changes in cognitive performance that were independent of changes in depressive symptoms. Findings suggest that cognitive function can be improved through targeted and repetitive cognitive remediation exercises in depressed patients; such cognitive training approaches have been shown to improve select cognitive abilities and may be of therapeutic value to those with other diseases. ${ }^{63}$

In addition to addressing disease symptoms and corresponding cognitive impairments, for some patients, jobs skills may have been forgotten over time or become outdated such that employment reintegration is more problematic. Therefore, occupational rehabilitation may be considered. For example, in a sample of seven unemployed African American gay men with HIV $\left(\mathrm{M}_{\text {age }}=46.1\right)$, Hergenrather et al delivered a didactic intervention designed to improve employment seeking that was administered in weekly 3-hour group sessions 
over a 7-week period. ${ }^{64}$ After 3 months, these researchers observed that one participant became a part-time employee, three enrolled in college classes, and three were actively pursuing employment. This pilot intervention suggests such job coaching may be effective in helping adults with HIV return to work at least part-time, or perhaps other activities (i.e., college classes) may be pursued that can be cognitively stimulating. Thus, consultation with a social worker and/or occupational therapist should be consulted for those patients who express interest in employment reintegration.

\section{Compensating with other stimulating activities}

Even with a lack of employment due to diseases or retirement, there remain several strategies through which patients can reap cognitive benefits that employment provides. Staying involved in learning new activities, socializing with friends and family, and engaging in cognitive improvement and/ or remediation training represent ways to support positive neuroplasticity and cognitive reserve.

One way to optimize cognitive reserve is through staying active in community and social events. As discussed earlier, Park et al and Seinfeld et al found that those older adults assigned to be actively engaged in learning a new skill (e.g., photography, piano) experienced improvement in cognitive functioning. ${ }^{1,11}$ A practical suggestion to patients who are unemployed may be to join clubs or organizations that offer classes in various topics of interest. Also, actively pursuing and participating in new hobbies and interests may promote positive neuroplasticity and optimal cognitive reserve to some degree.

Another way to promote cognitive reserve is socializing. As seen in this literature review, socializing is very cognitively stimulating; one must utilize many different executive functioning skills to respond and react accordingly to the complex social interactions one is engaged in. ${ }^{13-15}$ Given the milieu of rich social interactions, neuroscientists assert its importance in promoting positive neuroplasticity and cognitive reserve. ${ }^{65}$ A practical suggestion to patients who are unemployed would be to engage in more social interaction with friends and family and perhaps volunteer in community organizations and charities.

\section{Implications for research}

This relationship between employment, cognition, and diseases is complex and difficult to research for several reasons. For the sake of brevity, this section provides a discussion of only three such areas in which studying this relationship can be a challenge; these areas are: time of cognitive change with employment status; fluctuations of employment across the lifespan; and variations in environmental stress/press from employment.

\section{Longitudinal cognitive change with employment status}

Despite extensive searches in the literature, for this article, studies examining cognitive change when people return to work could not be found. There are several studies that show that, as people develop a disease or chronic condition, they either: 1) develop cognitive impairments and reduce the hours they work or 2) they have to reduce work due to treatment and then report cognitive impairments; but it is unclear whether the cognitive impairments are due to the loss of employment or treatment of their disease, or perhaps a combination of both. ${ }^{49,66,67}$ Carefully planned longitudinal studies are needed to show what happens to the cognition of those with certain diseases as they leave and reintegrate back into employment.

\section{Fluctuation of employment status across the lifespan}

Since there are fluctuations in cognitive functioning as well as employment status across the lifespan, many confounding issues interfere with the ability to examine both the cause and effect relationship between the two. First, assessing the quality and amount of employment as it relates to cognitive stimulation can be rather arbitrary. Using the Hollingshead four-factor index, types of occupation/employment is classified using a heirarchy from least prestigious/skilled (1= lowest) to most prestigious/skilled ( $9=$ highest $)$. As a point of reference, dishwashers are 1, garbage collectors are 2, chauffeurs are 3 , bakers are 4 , bank tellers are 5 , air traffic controllers are 6 , insurance adjusters are 7 , nurses are 8 , and physicians are $9 .{ }^{68}$ Inherent issues emerge; for instance, can one argue that MDs have more cognitive stimulation and more cognitive reserve than nurses? Even within professional circles on this hierarchy, employment-related cognitive stimulation can vary widely. For example, not all nurses are the same. One nurse may have over 20 years of an enriched and diverse practice including the emergency room, nursing home, psychiatric unit, oncology clinic, rehabilitation facility, and be a licensed nurse practitioner. Another nurse may have only 5 years of practice, all in the nursing home. According to this classification system, they both would be classified at the same occupational level but, when considering their experience, they are not cognitively stimulated the same by their employment. Simple occupational classification as a proxy for employment-related cognitive stimulation is not without issues. Yet, despite these issues, researchers continue to find 
that socioeconomic status measured with this classification system is associated with better cognitive functioning in older adults. ${ }^{69}$ Thus, researchers will need to be attentive to these issues when assessing the effects of employment type on cognitive reserve.

\section{Variation in environmental pressure from employment}

Employment can vary in how much pressure or stress it exerts on an individual; for some people the same job can produce a crippling amount of arousal, while for others with perhaps better coping abilities, such arousal may be highly stimulating and facilitate positive neuroplasticity. The interaction between employment, neuroplasticity, and cognitive reserve can also be researched and conceptualized by adapting the Yerkes-Dodson model of performance to learning (Figure 2) and applying parallels to cognitive reserve. The Yerkes-Dodson model ${ }^{70}$ posits that when one is engaged in learning a task, if it is of little interest or there are no or little consequences for learning it (i.e., low stress), the amount and success of learning will be low. On the other end, when one must learn a task, if it is of high interest with dire consequences for failure to the point of panic, such distress and extreme arousal actually interferes with the learning process; again, the amount and success of learning will be low. Instead, what has been observed is that when one is optimally aroused and there are moderate consequences for learning the task (i.e., eustress), the amount and success of learning will be high.

In the enriched environmental paradigm discussed earlier, rats placed in the impoverished environment would have very little interest in the task of exploring their environment because they are placed there in isolation with no toys. Rats placed in the standard environment would have some interest in exploring their environment because at least they could play with other rats. Then rats placed in the enriched environment would be optimally aroused as they would have several rats and toys to capture their interest. As already observed, compared to rats in the other environments, rats in the more aroused/interesting environments exhibited greater learning (i.e., positive neuroplasticity) and cognitive reserve, as demonstrated by better maze performance, more synaptodendritic connections, and larger/heavier brains. ${ }^{4-6}$

Similarly, in addition to the five benefits of employment that may be neuroprotective, employment arousal may also be a key factor in promoting learning, neuroplasticity, and cognitive reserve. If one is employed in a job that one perceives is dull, repetitive, and uninteresting with little pay, the neuroprotective and cognitive benefits may be small. Likewise, if one is employed in a job that one perceives has rigorous time, skill, and decision demands with high pay or with dire consequence, this stress may interfere with generating cognitive benefits, especially if the stress is chronic and one does not possess adequate coping skills. Again, chronic stress activates the HPA axis to release cortisol, which in the long term can cause neuroinflammation and reduce cognitive reserve. ${ }^{2}$ Theoretically, the ideal condition is to be employed whereby there is an optimal arousal and high level of interest with moderate consequences (e.g., good income, meaningful work). In fact, the psychological concept of "flow" is exemplified at this peak where one's abilities and interests match those of the task demands. ${ }^{71}$ Thus, being optimally aroused in one's employment could also provide higher levels of

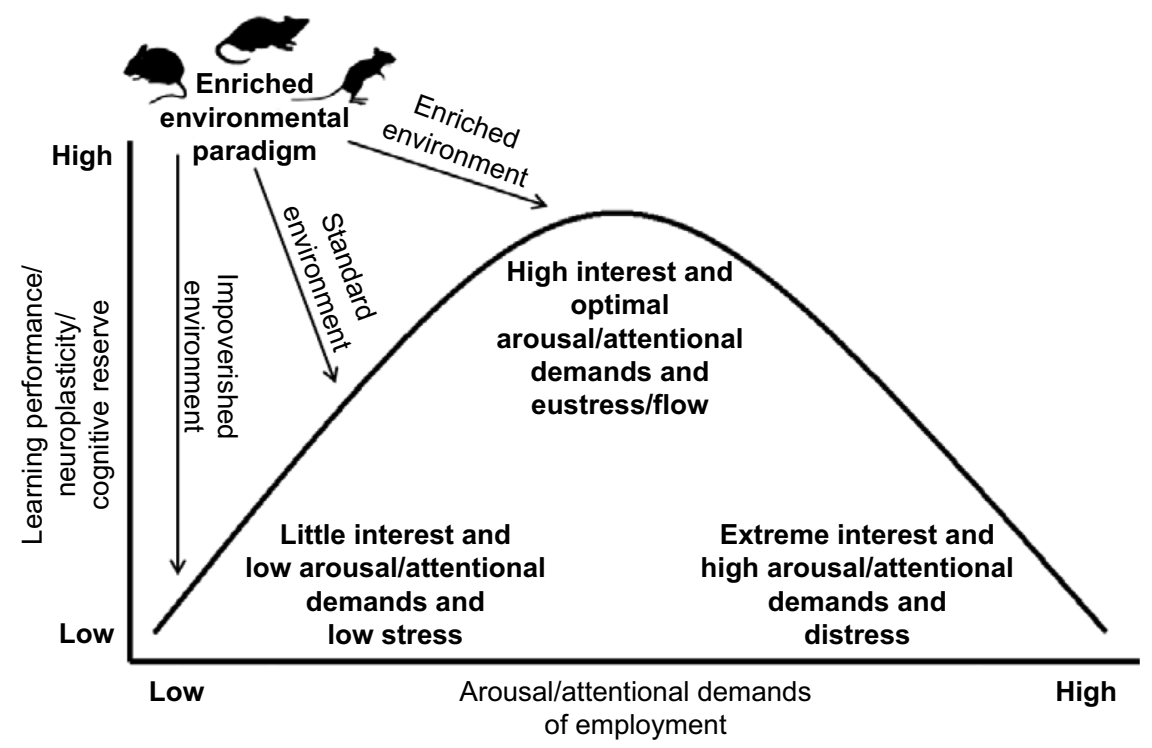

Figure 2 An adaptation of the Yerkes-Dodson model on neuroplasticity and cognitive reserve. Note: Data from Yerkes and Dodson. ${ }^{70}$ 
learning, positive neuroplasticity, and cognitive reserve, as has been alluded to in studies mentioned earlier. ${ }^{1}$

Notably, this model provides a framework where conceivably attentional demands of employment may not match the attentional skills of individuals. Some employment opportunities (e.g., grocery store cashier) may require moderate and sustained attentional skills necessary for successful engagement and to receive optimal cognitive benefit. Albeit, for many adults with diseases that negatively impact their cognition, attentional skills may be compromised such that the high attentional demand required from employment exceed the intrinsic attentional skills of the individual. This mismatch between person-environmental demands can result in distress and low cognitive benefit to the individual. Thus, this model can be used to understand how someone even in the same job, having different cognitive and attentional skills, can reap different cognitive benefits. This point is particularly salient to those with certain diseases who have varying levels of cognitive functioning in which they may or may not benefit from certain employment situations.

\section{Conclusion}

Environment, as observed with employment, can exert a profound influence on neuroplasticity and cognitive reserve. Unfortunately for those with diseases or chronic conditions who may have to reduce or stop employment, the lack of cognitive stimulation provided from engaging in employment can contribute to negative neuroplasticity and may compromise cognitive functioning. Clinicians may consider educating patients about the importance of staying cognitively active, either with or without employment, in order to promote successful cognitive aging. This phenomenon of how work impacts cognitive reserve is a largely unrecognized area of research that could lead to effective cognitive interventions for those with a variety of diseases and chronic conditions.

\section{Disclosure}

The authors report no conflicts of interest in this work.

\section{References}

1. Park DC, Lodi-Smith J, Drew L, Haber S, Hebrank A, Bischof GN, Aamodt W. The impact of sustained engagement on cognitive function in older adults: the Synapse Project. Psychol Sci. 2014;25(1):103-112.

2. Sartori AC, Vance DE, Slater LZ, Crowe M. The impact of inflammation on cognitive function in older adults: implications for healthcare practice and research. J Neurosci Nurs. 2012;44(4):206-217.

3. Sattler FR, He J, Letendre S, et al; CHARTER Group. Abdominal obesity contributes to neurocognitive impairment in HIV-infected patients with increased inflammation and immune activation. JAcquir Immune Defic Syndr. 2015;68(3):281-288.

4. Vance DE, Roberson AJ, McGuinness TM, Fazeli PL. How neuroplasticity and cognitive reserve protect cognitive functioning. J Psychosoc Nurs Ment Health Serv. 2010;48(4):23-30.
5. Diamond M. An optimistic view of the aging brain. Generations. 1993;17(1):31-33.

6. Kobayashi S, OhashiY, Ando S. Effects of enriched environments with different durations and starting times on learning capacity during aging in rats assessed by a refined procedure of the Hebb-Williams maze task. J Neurosci Res. 2002;70(3):340-346.

7. Lu L, Bao G, Chen H. Modification of hippocampal neurogenesis and neuroplasticity by social environments. Exp Neurol. 2003;183(2):600-609.

8. Boyke J, Driemeyer J, Gaser C, Büchel C, May A. Training-induced brain structure changes in the elderly. $J$ Neurosci. 2008;28(28):7031-7035.

9. Fisher GG, Stachowski A, Infurna FJ, Faul JD, Grosch J, Tetrick LE. Mental work demands, retirement, and longitudinal trajectories of cognitive functioning. J Occup Health Psychol. 2014;19(2):231-242.

10. Leist AK, Glymour MM, Mackenbach JP, van Lenthe FJ, Avendano M. Time away from work predicts later cognitive function: differences by activity during leave. Ann Epidemiol. 2013;23(8):455-462.

11. Seinfeld S, Figueroa H, Ortiz-Gil J, Sanchez-Vives MV. Effects of music learning and piano practice on cognitive function, mood and quality of life in older adults. Front Psychol. 2013;4:810.

12. Vance DE, Cody SL, Yoo-Jeong M, Jones GL, Nicholson WC. The role of employment on neurocognitive reserve in adults with HIV: a review of the literature. J Assoc Nurses AIDS Care. 2015;26(4):316-329.

13. de Frias CM, Dixon RA. Lifestyle engagement affects cognitive status differences and trajectories on executive functions in older adults. Arch Clin Neuropsychol. 2014;29(1):16-25.

14. Jedrziewski MK, Ewbank DC, Wang H, Trojanowski JQ. The impact of exercise, cognitive activities, and socialization on cognitive function: results from the national long-term care survey. Am J Alzheimers Dis Other Demen. 2014;29(4):372-378.

15. Dickinson WJ, Potter GG, Hybels CF, McQuoid DR, Steffens DC. Change in stress and social support as predictors of cognitive decline in older adults with and without depression. Int J Geriatr Psychiatry. 2011;26(12):1267-1274.

16. Saczynski JS, Pfeifer LA, Masaki K, Korf ES, Laurin D, White L, Launer LJ. The effect of social engagement on incident dementia: the Honolulu-Asia Aging Study. Am J Epidemiol. 2006;163(5):433-440.

17. Wang XS, Armstrong ME, Cairns BJ, Key TJ, Travis RC. Shift work and chronic disease: the epidemiological evidence. Occup Med (Lond). 2011;61(2):78-89.

18. Vance DE, Eagerton G, Harnish B, McKie-Bell P, Fazeli PL. Cognitive prescriptions across the lifespan: a nursing approach to increasing cognitive reserve. J Geront Nurs. 2011;37(4):22-29; quiz 30-31.

19. Matuska K. The healthy harvest. OTJR (Thorofare NJ). 2013;33(4):179.

20. Hakanen JJ, Schaufeli WB. Do burnout and work engagement predict depressive symptoms and life satisfaction? a three-wave seven-year prospective study. J Affect Disord. 2012;141(2-3):415-424.

21. Stevens-Ratchford R. Longstanding occupation: the relation of the continuity and meaning of productive occupation to life satisfaction and successful aging. Act Adapt Aging. 2011;35(2):131-150.

22. White CP, Lentin, Farnworth L. Multimorbidity and the process of living with ongoing illness. Chronic Illn. 2016;12(2):83-97.

23. Sultan-Taieb H, Chastang JF, Mansouri M, Niedhammer I. The annual costs of cardiovascular diseases and mental disorders attributable to job strain in France. BMC Public Health. 2013;13:748.

24. O'Connor TM, O'Halloran DJ, Shanahan F. The stress response and the hypothalamic-pituitary-adrenal axis: from molecule to melancholia. QJM. 2000;93(6):323-333.

25. Kalousova L, Burgard SA. Unemployment, measured and perceived decline of economic resources: contrasting three measures of recessionary hardships and their implications for adopting negative health behaviors. Soc Sci Med. 2014;106:28-34.

26. Ayers JW, Althouse BM, Allem JP. Novel surveillance of psychological distress during the great recession. JAffect Disord. 2012;142(1-3):323-330.

27. Noice H, Noice T, Staines G. A short-term intervention to enhance cognitive and affective functioning in older adults. JAging Health. 2004; 16(4):562-585. 
28. Vance DE, Fazeli PL, Dodson JE, Ackerman M, Talley M, Appel SJ. Comorbidities and cognitive functioning: implications for nursing practice and research. J Neurosci Nurs. 2011;43(4):215-224.

29. Schwartz CE, Ayandeh A, Ramanathan M, Benedict R, Dwyer MG, Weinstock-Guttman B, Zivadinov R. Reserve-building activities in multiple sclerosis patients and healthy controls: a descriptive study. BMC Neurol. 2015;15:135.

30. Hees HL, Koeter MW, Schene AH. Predictors of long-term return to work and symptom remission in sick-listed patients with major depression. J Clin Psychiatry. 2012;73(8):e1048-e1055.

31. Evans VC, Alamian G, McLeod J, Woo C, Yatham LN, Lam RW. The effects of newer antidepressants on occupational impairment in major depressive disorder: a systematic review and meta-analysis of randomized controlled trials. CNS Drugs. 2016;30(5):405-417.

32. Lerner D, Adler DA, Chang H, et al. Unemployment, job retention, and productivity loss among employees with depression. Psychiatr Serv. 2004;55(12):1371-1378.

33. Schoenbaum M, Unützer J, Sherbourne C, et al. Cost-effectiveness of practice-initiated quality improvement for depression: results of a randomized controlled trial. JAMA. 2001;286(11):1325-1330.

34. Simon GE, Chisholm D, Treglia M, Bushnell D; LIDO Group. Course of depression, health services costs, and work productivity in an international primary care study. Gen Hosp Psychiatry. 2002;24(5):328-335.

35. Byers AL, Yaffe K. Depression and risk of developing dementia. Nat Rev Neurol. 2011;7(6):323-331.

36. Baune BT, Miller R, McAfoose J, Johnson M, Quirk F, Mitchell D. The role of cognitive impairment in general functioning in major depression. Psychiatry Res. 2010;176(2-3):183-189.

37. Lam RW, Michalak EE, Bond DJ, Tam EM, Axler A, Yatham LN. Which depressive symptoms and medication side effects are perceived by patients as interfering most with occupational functioning? Depress Res Treat. 2012;2012:630206.

38. Vance DE, Mugavero M, Willig J, Raper JL, Saag MS. Aging with HIV: a cross-sectional study of comorbidity prevalence and clinical characteristics across decades of life. JAssoc Nurses AIDS Care. 2011;22(1):17-25.

39. Plessis SD, Vink M, Joska JA, Koutsilieri E, Stein DJ, Emsley R. HIV infection and the fronto-striatal system: a systematic review and metaanalysis of fMRI studies. AIDS. 2014;28(6):803-811.

40. Thames AD, Streiff V, Patel SM, Panos SE, Castellon SA, Hinkin CH. The role of HIV infection, cognition, and depression in risky decisionmaking. J Neuropsychiatry Clin Neurosci. 2012;24(3):340-348.

41. Vance DE, Moneyham L, Fordham P, Struzick TC. A model of suicidal ideation in adults aging with HIV. J Assoc Nurses AIDS Care. 2008;19(5):375-384.

42. McManus H, Petoumenos K, Franic T, et al. Australian HIV Observational Database. Determinants of suicide and accidental or violent death in the Australian HIV Observational Database. PLoS One. 2014;9(2):e89089.

43. van Gorp WG, Rabkin JG, Ferrando SJ, Mintz J, Ryan E, Borkowski T, McElhiney M. Neuropsychiatric predictors of return to work in HIV/ AIDS. J Int Neuropsychol Soc. 2007;13(1):80-89.

44. Fazeli PL, Woods SP, Heaton RK, et al. An active lifestyle is associated with better neurocognitive functioning in adults living with HIV infection. J Neurovirol. 2014;20(3):233-242.

45. American Cancer Society. Breast Cancer Facts and Figures 2013-2014. American Cancer Society: Atlanta, GA; 2013.

46. Pullens MJ, De Vries J, Roukema JA. Subjective cognitive dysfunction in breast cancer patients: a systematic review. Psychooncology. 2010;19(11):1127-1138.

47. Bower JE. Behavioral symptoms in patients with breast cancer and survivors. J Clin Oncol. 2008;26(5):768-777.

48. Frank JS, Vance DE, Jukkala A, Meneses KM. Attention and memory deficits in breast cancer survivors: implications for nursing practice and research. J Neurosci Nurs. 2014;46(5):274-284.

49. Becker H, Henneghan A, Mikan SQ. When do I get my brain back? Breast cancer survivors' experiences of cognitive problems. Clin JOncol Nurs. 2015;19(2):180-184.
50. Boykoff N, Moieni M, Subramanian SK. Confronting chemobrain: an in-depth look at survivors' reports of impact on work, social networks, and health care response. J Cancer Surviv. 2009;3(4):223-232.

51. Munir F, Kalawsky K, Lawrence C, Yarker J, Haslam C, Ahmed S. Cognitive intervention for breast cancer patients undergoing adjuvant chemotherapy: a needs analysis. Cancer Nurs. 2011;34(5):385-392.

52. Von Ah D, Habermann B, Carpenter JS, Schneider BL. Impact of perceived cognitive impairment in breast cancer survivors. Eur J Oncol Nurs. 2013;17(2):236-241.

53. Player L, Mackenzie L, Willis K, Loh SY. Women's experiences of cognitive changes or 'chemobrain' following treatment for breast cancer: a role for occupational therapy? Aust Occup Ther J. 2014;61(4): 230-240.

54. Munir F, Burrows J, Yarker J, Kalawsky K, Bains M. Women's perceptions of chemotherapy-induced cognitive side affects on work ability: a focus group study. J Clin Nurs. 2010;19(9-10):1362-1370.

55. Timperi AW, Ergas IJ, Rehkopf DH, Roh JM, Kwan ML, Kushi LH. Employment status and quality of life in recently diagnosed breast cancer survivors. Psychooncology. 2013;22(6):1411-1420.

56. Hauglann B, Benth JŠ, Fosså SD, Dahl AA. A cohort study of permanently reduced work ability in breast cancer patients. J Cancer Surviv. 2012;6(3):345-356.

57. Lindbohm ML, Kuosma E, Taskila T, Hietanen P, Carlsen K, Gudbergsson S, Gunnarsdottir H. Early retirement and non-employment after breast cancer. Psychooncology. 2014;23(6):634-641.

58. Wilson RS, Boyle PA, Yu L, Barnes LL, Schneider JA, Bennett DA. Life-span cognitive activity, neuropathologic burden, and cognitive aging. Neurology. 2013;81(4):314-321.

59. Lindstrom HA, Fritsch T, Petot G, et al. The relationships between television viewing in midlife and the development of Alzheimer's disease in a case-control study. Brain Cogn. 2005;58(2):157-165.

60. Wang PS, Simon GE, Avorn J. Telephone screening, outreach, and care management for depressed workers and impact on clinical and work productivity outcomes: a randomized controlled trial. JAMA. 2007;298(12):1401-1411.

61. Dewa CS, Thompson AH, Jacobs P. The association of treatment of depressive episodes and work productivity. Can J Psychiatry. 2011;56(12): 743-750.

62. Elgamal S, McKinnon MC, Ramakrishnan K, Joffe RT, MacQueen G. Successful computer-assisted cognitive remediation therapy in patients with unipolar depression: a proof of principle study. Psychol Med. 2007;37(9): 1229-1238.

63. Lampit A, Hallock H, Valenzuela M. Computerized cognitive training in cognitively healthy older adults: a systematic review and meta-analysis of effect modifiers. PLoS Med. 2014;11(11):e1001756.

64. Hergenrather KC, Geishecker S, Clark G, Rhodes SD. A pilot test of the HOPE Intervention to explore employment and mental health among African American gay men living with HIV/AIDS: results from a CBPR study. AIDS Educ Prev. 2013;25(5):405-422.

65. Gheusi G, Ortega-Perez I, Murray K, Lledo PM. A niche for adult neurogenesis in social behavior. Behav Brain Res. 2009;200(2):315-322.

66. Pike J, Jones E, Rajagopalan K, Piercy J, Anderson P. Social and economic burden of walking and mobility problems in multiple sclerosis. BMC Neurol. 2012;12:94.

67. Kennedy M, Papneja A, Thavaneswaran A, Chandran V, Gladman DD. Prevalence and predictors of reduced work productivity in patients with psoriatic arthritis. Clin Exp Rheumatol. 2014;32(3):342-348.

68. Hollingshead AB. Four factor index of social status. Yale J Soc. 2011;8: 21-51.

69. Qian W, Schweizer TA, Fischer CE. Impact of socioeconomic status on initial clinical presentation to a memory disorders clinic. Int Psychogeriatr. 2014;26(4):597-603.

70. Yerkes RM, Dodson JD. The relation of strength of stimulus to rapidity of habit-formation. J Comp Neurol. 1908;18:459-482.

71. Csikszentmihalyi MS, Abuhamdeh S, Nakamura J. Flow. In: Handbook of Competence and Motivation. Elliot A, Editor. New York, NY: Guilford Press; 2005:598-698. 
Nursing: Research and Reviews is an international, peer-reviewed, open access journal publishing original research, reports, reviews and commentaries on all aspects of nursing and patient care. These include patient education and counseling, ethics, management and organizationa issues, diagnostics and prescribing, health outcomes, economics and
Dovepress

resource management, improving patient safety in all settings. The manuscript management system is completely online and includes a very quick and fair peer-review system. Visit http://www.dovepress. com/testimonials.php to read real quotes from published authors.

Submit your manuscript here: https://www.dovepress.com/nursing-research-and-reviews-journal 